\title{
A second brain tumour and irradiation
}

\author{
R I C H A R D G. R O B I N S O N \\ From the Neurosurgical Unit and Department of Surgery, University of Otago Medical School, \\ Dunedin, New Zealand
}

SUMMARY Three patients are described in whom irradiation of $2750 \mathrm{rad}$ or more was used in the management of primary brain tumours, and 21 years or more later a second brain tumour of a different type occurred. One of the new tumours was a meningioma and the other two were cerebral astrocytomas. There is evidence to show that moderate doses of ionising radiations given in childhood for tinea capitis are associated with a late risk of developing a meningioma. Higher doses of radiation used for tumours in childhood are followed also by a late hazard of meningioma. There is insufficient evidence to implicate ionising radiations in the aetiology of gliomas. The oncogenic hazards of radiotherapy to the brain do not outweigh its therapeutic value in brain tumour.

Although the simultaneous occurrence of two primary brain tumours of either the same or different types is recognised but not common, the consecutive development of brain tumours after a long time interval has rarely been recorded (Behrend, 1974). So far, most have been in the phakomatoses. While ionising radiations are a potent carcinogen, only exceptionally have they been postulated in the aetiology of brain tumours. In this paper I report three patients with primary brain tumour who 21 years or more later had a second brain tumour of a different type. All had been given radiotherapy as part of their initial treatment.

\section{Patients}

CASE 1

A male (NS 573), born on 1 February 1935, had a two year history of headaches and recent vomiting and diplopia when he was admitted on 5 January 1945. There was papilloedema, left sixth cranial nerve palsy, and mild generalised ataxia.

Ventriculography showed a round mass in the posterior end of the third ventricle which contained a little calcium. A posterior fossa craniotomy revealed no abnormality. On recovery the patient was given radiotherapy to the pineal region from

Address for reprint requests : Professor R. G. Robinson, Department of Surgery, University of Otago Medical School, Dunedin, New Zealand. Accepted 6 June 1978 a $200 \mathrm{kV}$ source. The estimated dose was $4000 \mathrm{rad}$ given over 23 days through multiple ports.

He was readmitted on 21 October 1945 with signs of deterioration. By a right parasagittal approach the pineal area was explored and a circumscribed tumour removed. The tumour weighed $18 \mathrm{~g}$ and had a smooth capsule. On section it contained hairs, cheesy material, and one part was calcified. A diagnosis of pineal teratoma was made.

He remained well and gained employment as an assistant in the Post Office. On 31 March 1971 he was admitted with a year's history of slowing up, and weakness of the left side for two months. There was considerable epilation of the scalp. $\mathrm{He}$ had a left hemiparesis. An isotope brain scan and a right carotid arteriogram indicated a right frontal tumour. At operation a right frontal glioma was partly removed, and on histological examination, this was found to be an astrocytoma grade 4 (Fig. 1). He died at home on 9 December 1971. A limited necropsy was done.

The fixed brain weighed $1200 \mathrm{~g}$. The dura mater was adherent to the right frontal and parietal areas. On serial section there was an extensive neoplasm in the right hemisphere which had spread into the left (Fig. 2). The pineal gland was absent. On histological examination the tumour was an astrocytoma grade 4 (glioblastoma multiforme). No radiation changes were seen in the surrounding brain.

The tumour removed in 1945 was a typical 


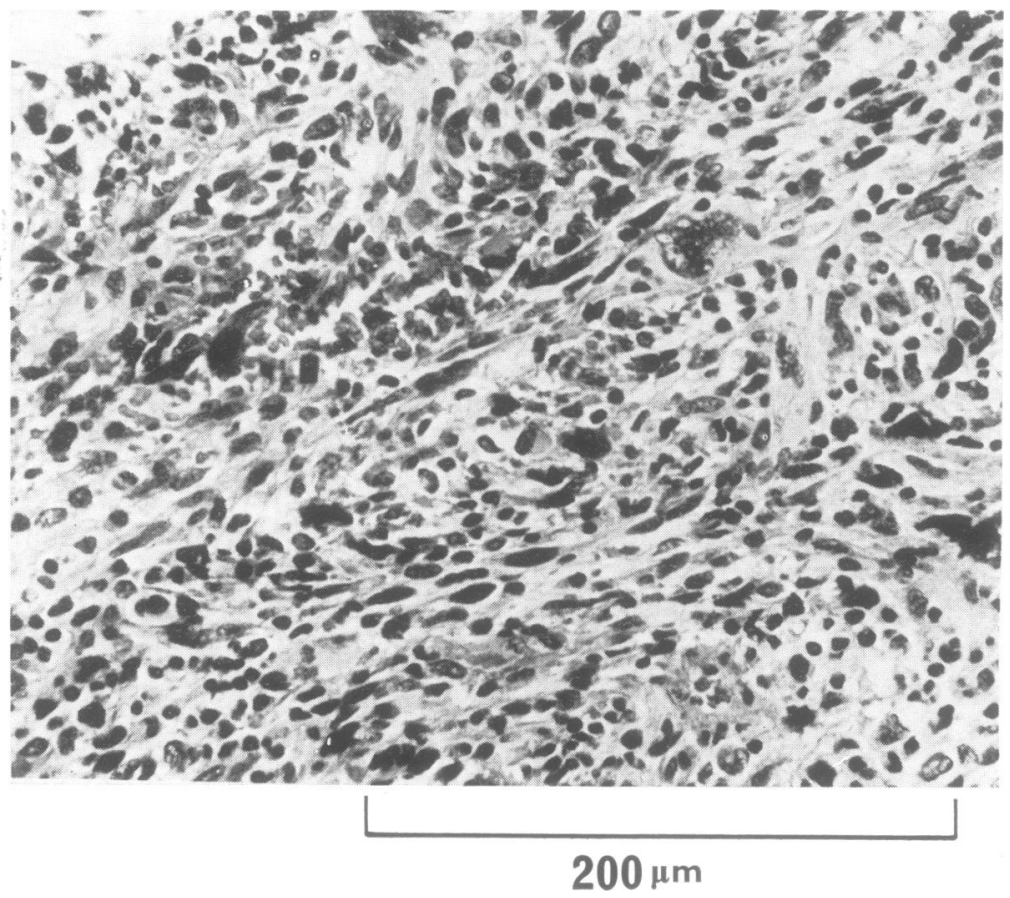

Fig. 1 Case 1. Biopsy specimen from right frontal area showing astrocytoma grade 4 (glioblastoma multiforme). (Haematoxylin and eosin)
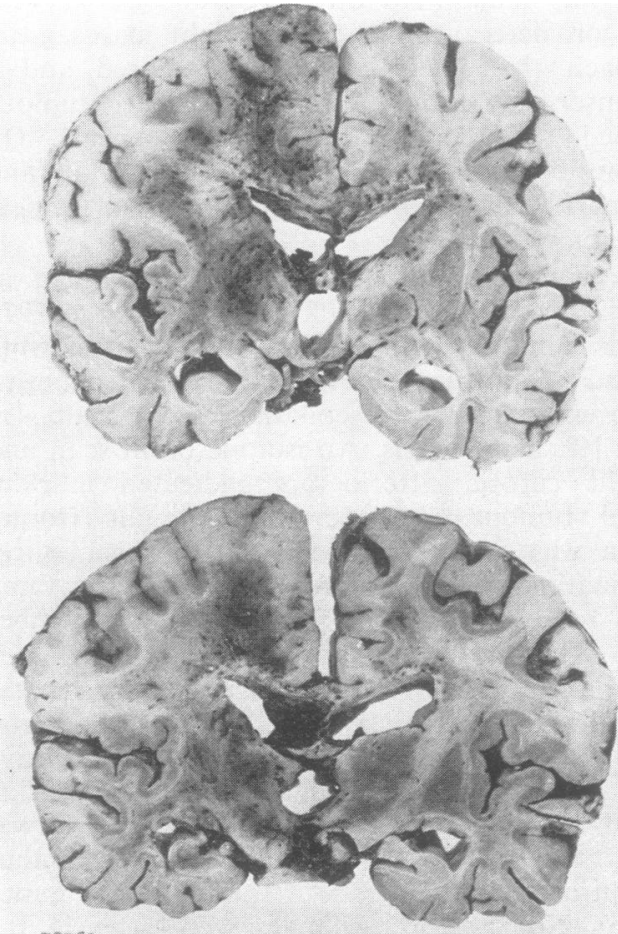

72369

pineal teratoma and benign (Russell and $\stackrel{\frac{\rho}{\circ}}{\frac{1}{2}}$ Rubinstein, 1971). Sections of fragments of the $\_-$ wall were extant in 1972 , and a re-examination $z$ was in agreement with the original diagnosis.

CASE 2

응 市

A male (NS 4135), born on 10 January 1915, was $\stackrel{\vec{F}}{\vec{\varphi}}$ admitted on 1 May 1951 after a major epileptic fit. There were no abnormal physical signs. A right carotid arteriogram showed a large vascular meningioma filling the middle fossa. At operation this was only partially removed because of the bleeding. With a view to reducing the vascularity the patient was given radiotherapy from a $200 \mathrm{kV}$ source when 2750 rad were given over 39 days through multiple ports. At the second operation on 10 October 1951 a $25 \mathrm{~g}$ avascular meningioma was removed from the inner end of the sphenoidal ridge. On histological section the first tumour was a transitional meningioma (Fig. 3), and the second had irradiation changes.

Bowel symptoms occurred early in 1965 and an abdominoperineal resection of the rectum was done for a low well-differentiated adenocarcinoma, Dukes grade B.

Fig. 2 Case 1. Coronal sections of the brain showing extensive glioma in the right and left cerebral hemispheres. 


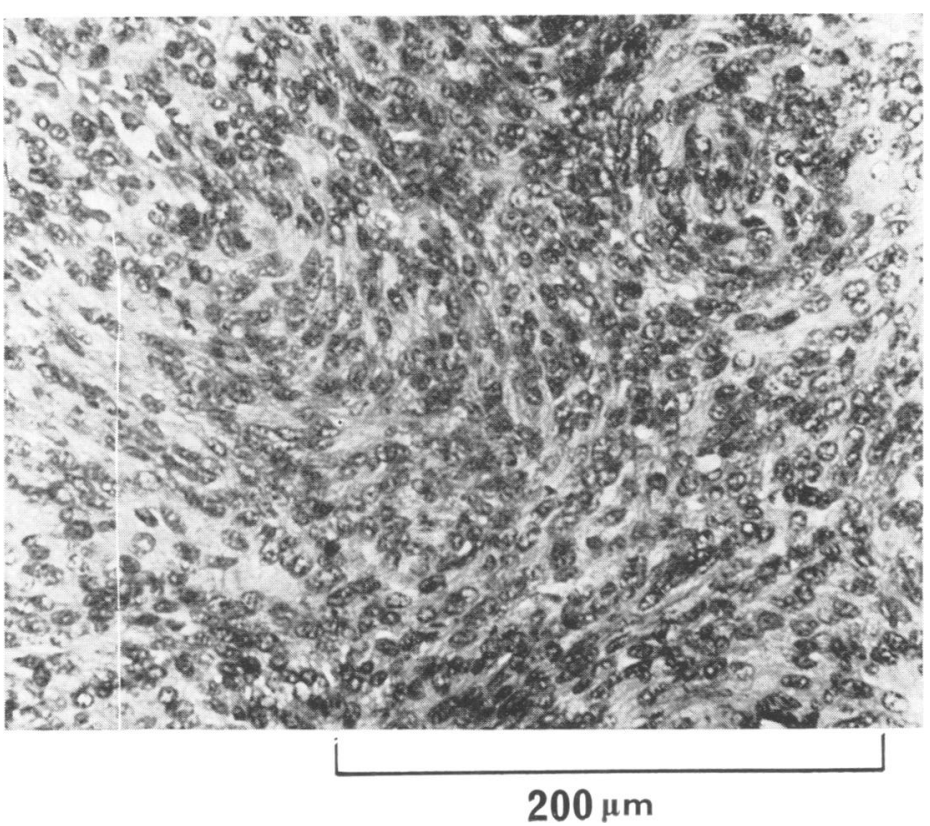

Fig. 3 Case 2. Transitional type meningioma of sphenoidal ridge. ( $H$ and $E$ )
He was admitted on 28 December 1972 with a six month history of deterioration of his farming ability and clumsiness of the left hand. There was a left homonymous hemianopia and a left hemiparesis. An isotope brain scan indicated a mass in the right temporal area which was avascular on carotid arteriography. At operation the middle fossa was occupied by a large neoplastic cyst containing $50 \mathrm{ml}$ of xanthochromic fluid. There was no evidence of a recurrence of the meningioma or of the presence of a secondary carcinoma, and no radiation changes. The tumour was an astrocytoma grade 3 (Fig. 4). He died at home on 27 June 1973, and no necropsy was done.

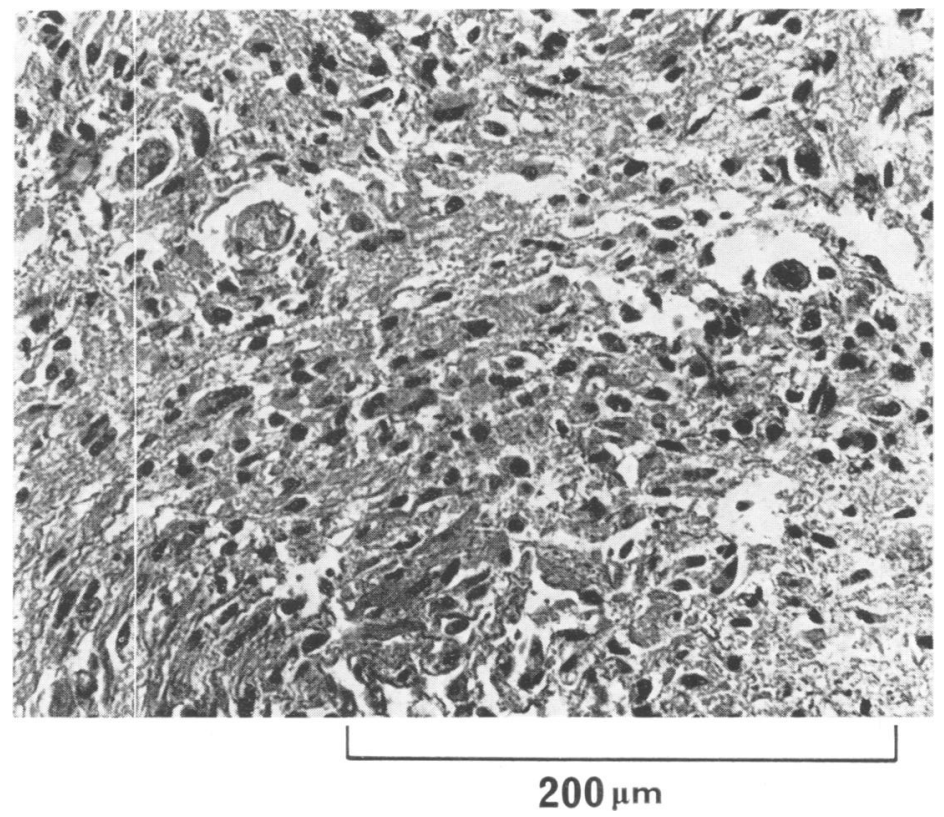

Fig. 4 Case 2. Astrocytoma grade 3 at the same site as Fig. 3, 21 years later. $(H$ and $E)$ 
CASE 3

A single female (NS 18146), born on 27 January 1941 , was admitted on 22 June 1975 . Since early 1974 the vision of the right eye had deteriorated and that of the left had become hazy.

She had been operated upon at the age of 12 years in 1953 at Pendelbury Hospital. A tumour had bee $n$ biopsied in the cerebellum. It was a round-cell tumour but it was uncertain whether this was a medulloblastoma or a glioblastoma. At the Christie Hospital and Holt Radium Institute, Manchester, she was given whole nervous system irradiation. The minimum dose was $3000 \mathrm{rad}$ given over three weeks. The dose to the frontal region and to the back of the head was estimated to have been $3500 \mathrm{rad}$ in three weeks. As a result of this illness she had been left with partial left sixth and seventh cranial nerve palsies and ataxia of the left arm and leg.

She emigrated to New Zealand in 1960. She had persisting bowel symptoms and laparotomies were done in 1963 and 1969. The large bowel was removed for confirmed Crohn's disease and she had a terminal ileostomy.

There was bilateral optic atrophy: vision, right, counts fingers; left, N5 corrected. All that remained of the right visual field was an inferior nasal island to a finger, the left field had a small temporal defect to $1 / 1000$ white. There was nystagmus in all directions, partial left sixth and seventh cranial nerve palsies and left sided ataxia.
The radiograph of the skull was normal apart from signs of the previous operation. A right carotid arteriogram showed the anterior cerebral artery to be elevated over an avascular suprasellar mass. At lumbar encephalography the fourth ventricle and aqueduct were normal. The lateral ventricles were small and not displaced. There was air over the top of a suprasellar tumour, $30 \mathrm{~mm}$ in diameter, which indented the floor of the third ventricle. At operation a suprasellar meningioma $30 \mathrm{~mm}$ across was removed. It had encircled the right optic nerve. Histological examination showed that the tumour was a transitional type of meningioma (Fig. 5).

Her vision on 29 September 1975 was, right N8 and left N5, corrected. The right visual field was full nasally and the temporal field was half of full; the left field was full. There was no change on the other neurological deficits.

\section{Discussion}

These consecutive brain tumours must be seen against the natural expectancy for such in a life- $-\stackrel{+}{+}$ time. Generally it is agreed that having survived $\overrightarrow{0}$ the treatment of one neoplasm the expectancy $\frac{\pi}{0}$ or of developing another is as if the first had not? occurred. However, Theodore Billroth in $1889 \AA$ (Schoenberg et al., 1969) postulated that a persono $z$ who had had one cancer was more than normallyo prone to develop another. This hypothesis has beeno

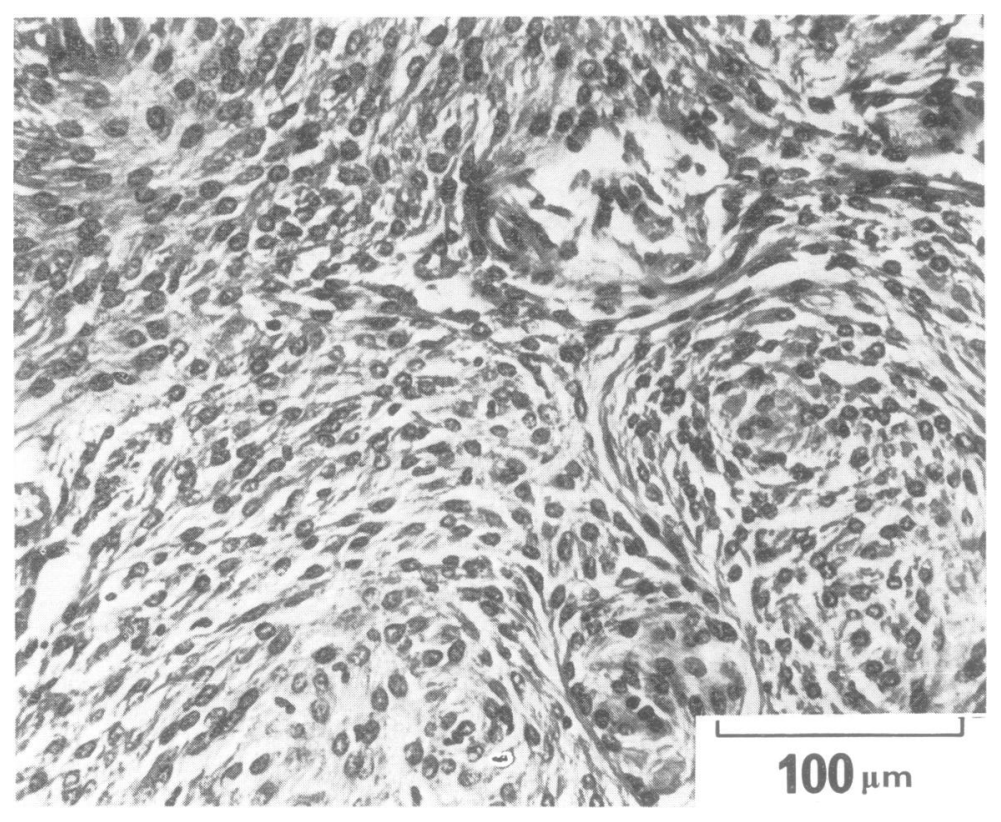

Fig. 5 Case 3. Transitional type meningioma of suprasellar region. ( $H$ and $E$ ) 
a matter of controversy, and the current view is that there is no such trend except in special sites, such as skin, large bowel, and female genital organs (Schoenberg et al., 1969). Should a third cancer develop then there is a susceptibility to cancer (Moertal, 1966).

Leaving the phakomas aside, simultaneous brain tumours of a wide variety are known but not common, but whether this is more than a chance finding is unknown (Russell and Rubinstein, 1971; Behrend, 1974). The natural expectancy for a primary brain tumour is of the order of 8.5/10000 population per year for all ages (Kurland, 1958). The adult expectancy for a glioma is $3.9 / 100000$ population per year, and that for a meningioma is 1.23/100 000 (Barker et al., 1976). Whether the late possibility of a second brain tumour reaches natural expectancy has never been studied. Radiotherapy has enabled some patients with brain tumour in childhood to have prolonged survival, and patients may live for long periods after the treatment of a pituitary adenoma or a meningioma. It is these patients who are at risk for second brain tumour, but accurate data are lacking. In the nature of things gliomas should considerably outnumber meningiomas in the sequential situation.

Experimentally it is very difficult to induce tumours in the primate nervous system by whatever carcinogen is used. A few brain tumours have been induced by ionising radiations in monkeys in whom natural brain tumours are rare -five instances in 115000 monkeys (Haymaker et al., 1972). A glioblastoma multiforme in a Macacca mulatta was induced nearly two and a half years after exposure of the head to thermal neutrons (Kent and Pickering, 1958). When wholebody protons $600-800$ rad were given to $M$. mulatta, three glioblastomas were produced three to five years later. For animals who survived more than two years the risk was in excess of natural expectancy (Traynor and Casey, 1971; Haymaker et al., 1972).

In man, irradiation of the head in childhood may be followed many years later by a brain tumour, usually a meningioma. An obsolescent method of treating tinea capitis was to irradiate the scalp with 500-800 rad when the surface dose to the brain is about $140 \mathrm{rad}$. The treatment was used widely for nearly half a century from 1909 onwards until superseded by griseofulvin. It was not until 1966 that the serious long-term hazards of this treatment were reported. Of the nine neoplasms found in 1548 irradiated children there was one astrocytoma of the optic nerve and chiasma, and one cerebral astrocytoma (Albert et al., 1966). Then followed a report from Israel of five cases of intracranial meningioma after this treatment with latencies of 16 to 50 years (Munk et al., 1969), and there was another series of 16 cases (Beller et al., 1972). Nearly 16500 child immigrants to Israel in the period 1948-1951 were so treated, and from an analysis of some 11000 of these cases there is conclusive evidence of the role of such irradiation in the aetiology of brain tumour, particularly meningioma. The meningioma rate was $0.4 / 1000$ cases in the irradiated cases against $0.1 / 1000$ in the non-irradiated, a statistically significant difference. There was an excess of other brain tumours over the expected rate but not at significant levels (Modan et al., 1974). Probably not dissimilar dose-wise was the sphenoidal ridge meningioma that appeared 24 years after thorium dioxide ventriculography in childhood (Kyle et al., 1963). There is a report of a meningioma occurring 28 years after application of radium to the scalp for a vascular naevus in childhood (Feiring and Foer, 1968).

Seven intracranial meningiomas have been reported after earlier high-dose irradiation for other types of brain tumour when the dose was $2300 \mathrm{rad}$ or more. Six cases were in children or adolescents (Gautier-Smith, 1970, one case; Norwood et al., 1974, two cases; Bogdanowicz and Sachs, 1974, two cases; Tanaka et al., 1975, one case), and the seventh was in a young adult (Waga and Handa, 1976). The latent intervals between the two tumours were from 12 to 15 years. Our case 3 would be the eighth such case and the latent interval was 22 years. Also, it is likely that the meningeal sarcoma reported by Bojsen-Møller and Knudsen (1977) could be a meningioma, and this was a childhood case.

Occasionally sarcoma, often soft tissue, may follow therapeutic irradiation of the head. In a review by Waltz and Brownell (1966) there were 13 cases of sarcoma mainly in the sellar region after radiotherapy for pituitary adenoma, with latencies of two and a half years. An osteogenic sarcoma in the sellar region was reported 10 years after pituitary irradiation at 16 years of age by Amine and Sugar (1976). Waltz and Brownell (1966) also found six cases of superficial sarcoma after head irradiation for other kinds of brain tumour. There have been two other cases (Berg et al., 1966), and there are two reports of meningeal sarcoma after head irradiation (Schrantz and Aroaz, 1972; Komaki et al., 1977). The first two cases of malignant schwannoma of the spine after irradiation of the back for unrelated conditions have been reported, and this tumour occurs very rarely (Maurice-Williams and Lucey, 1975).

There are two previous accounts of glioma 
appearing after irradiation for other brain tumours. There was a patient with a left frontal angioblastic meningioma treated by partial removal and radiotherapy. Ten years later at necropsy the meningioma was still present but had become psammomatous, and there was a separate right frontal astrocytoma (Jones, 1960). The other case was of a young adult whose craniopharyngioma was treated by surgery and radiotherapy and who died six years later of a glioblastoma multiforme of the temporal lobe (Komaki et al., 1977). Cases 1 and 2 of this report are further instances of astrocytoma occurring long after irradiation and all the cases have been after irradiation in adult life. Case 2 had multiple consecutive neoplasms, meningioma, rectal cancer, and cerebral astrocytoma, and would be considered tumour prone (Moertal, 1966).

Ionising radiations are known to be carcinogenic for man with a considerable latent period. After exposure to radiations in fetal life, a 10 year survey gives a reasonable estimate of the total induced disease. For those exposed in adult life a 25 year survey underestimates the lifetime risk of carcinogenesis by a factor of at least two. The hazards for the infant and child are closer to the adult than to the fetal one (Mole, 1973). There have been various estimates of the late cancer risk, and one for whole-body irradiation is of the order of 200 cases per $10^{6}$ exposed per rad (Mole, 1973). When survivors of childhood malignancy who had been irradiated were followed, there was a cumulative probability of a second cancer of $12 \%$. The radiation-related cancer rate was 1.8 cases in exposed tissues per $10^{6}$ person-years per rad, with the peak incidence being 15 to 19 years after irradiation (Li et al., 1975). A more recent estimate is of $10^{-4}$ cases per rad of whole-body dose, and when a single organ is irradiated the risk is lowered by a factor of at least four (World Health Organisation Report of Expert Committee, 1977).

There is good evidence that moderate-dose irradiation of under 800 rad to the head in childhood is associated with a significant hazard of developing an intracranial meningioma many years later. With higher doses of irradiation, particularly when given in childhood, it would seem probable that there is still a risk of late meningioma. There might have been uncertainty about this and the occurrence of these new tumours could be within the bounds of normal expectancy. However, the evidence from the tinea capitis cases makes this unlikely. Thus ionising radiations are oncogenic for the meninges especially in childhood. This is the first positive example of such an induction agent being identified for meningeal tumours. Previously head trauma had been suggested as being responsible for some meningiomas, but the data never carried conviction (Russell and Rubinstein, 1971). The matter of dose-dependency is complex. While there is a linear relationship between dose and the incidence of neoplasia, above a certain dose the rate begins to fall (Mole, 1973, 1975). There is, for instance, evidence from the female pelvis that moderate doses of irradiation are more carcinogenic than high ones (Mole, 1973, 1975; Smith and Doll, 1976).

So far there have been eight meningiomas after earlier irradiation and four astrocytomas. This is a reversal of the usual meningioma/glioma ratio, and is supporting evidence for ionising radiations being a meningeal carcinogen over a wide range of doses. The actual risks are very small. If therapeutic radiation gives, say, a fivefold increase in the meningioma rate over the expected, or a little above the tinea capitis ratio, then thio would mean that in 100000 survivors from treate ment in childhood and adolescence there would be around six meningiomas per year instead of the natural expectancy of one or so. This increase $\frac{0}{0}$ o a life-time one, would not be apparent until 1œ years after treatment, and it might be 20 years before the maximum was reached. Further, man $z$ of these second tumours would be treatable. In those countries where irradiation on a wide scale was used for tinea capitis there should be an increase meningioma rate. The sarcoma risk, which is? mainly an adult one and most common with pituitary radiation, seems to be due to a mixture of factors. The target tended to be small, high doses were often given over a short period of time, and multiple-course techniques used and which have now been abandoned. The risk with modern radiotherapeutic techniques is an exceedingly small one (Bloom, 1977).

The evidence is less clear for brain astrocytoma being induced by ionising radiations, and if there is a hazard it is much smaller than the meningioma one. The few reported cases in adults might be within normal expectancy.

On available evidence there is nothing to indicate that the long-term neoplastic hazards of irradiation in any way outbalance the benefits of its calculated use for intracranial tumours at whatever age. However, its use for benign extracranial lesions of the head and neck cannot be supported at all (Cade, 1966).

Cases 2 and 3 were investigated by the clinical staff of Christchurch Hospital, Christchurch, and Dr 
K. E. Kibblewhite, Greymouth, obtained the brain of case 1. Considerable help in pathology was given by Associate Professor J. F. Gwynne in case 1, and by Associate Professor I. Aarons in cases 2 and 3, both of the University of Otago Medical School. The first operations on case 1 were done by $\mathrm{Mr} \mathrm{M}$. A. Falconer and on case 2 by Mr J. A. James, Dr D. H. J. Shine, Dunedin, kindly recalculated the dose of radiotherapy given to cases 1 and 2. Dr Dorothy Pearson, Christie Hospital and Holt Radium Institute, Manchester, England, gave the details of the first management of case 3 .

\section{References}

Albert, R. E., Omran, A. R., Brauer, E. W., Dove, D. C., Cohen, N. C., Schmidt, H., Baumring, R., Morrill, S., Schulz, R., and Baer, R. L. (1966). Follow-up study of patients treated by $\mathrm{x}$-rays for tinea capitis. American Journal of Public Health, 56, $2114-2120$.

Amine, A. R. C., and Sugar, O. (1976). Suprasellar osteogenic sarcoma following radiation for pituitary adenoma. Journal of Neurosurgery, 44, 88-91.

Barker, D. J. P., Weller, R. O., and Garfield, J. S. (1976). Epidemiology of primary tumours of the brain and spinal cord: a regional survey in southern England. Journal of Neurology, Neurosurgery, and Psychiatry, 39, 290-296.

Behrend, R. Ch. (1974). Epidemiology of brain tumours. In Handbook of Clinical Neurology, volume 16 , pp. 56-88. Edited by P. J. Vinken and G. W. Bruyn. North-Holland: Amsterdam.

Beller, A. J., Feinsod, M., and Sahar, A. (1972). The possible relationship between small dose irradiation to the scalp and intracranial meningiomas. Neurochirurgia (Stuttgart), 15, 135-143.

Berg, N. O., Landberg, T., and Lindgren, M. (1966). Osteonecrosis and sarcoma following external irradiation of intracerebral tumours. Acta Radiologica, Therapy, Physics, Biology, 4, 417-436.

Bloom, H. G. (1977). The role of radiotherapy in the management of chiasmal compression. Proceedings of the Royal Society of Medicine, 70, 319-326.

Bogdanowicz, W. M., and Sachs, E. (1974). The possible role of radiation in oncogenesis of meningioma. Surgical Neurology, 2, 379-383.

Bojsen-Møller, M., and Knudsen, V. (1977). Radiationinduced meningeal sarcoma. Acta Neurochirurgica, 37, 147-152.

Cade, S. (1966). Iatrogenics. Clinical Radiology, 17, 193-202.

Feiring, E. H., and Foer, W. H. (1968). Meningioma following radium therapy. Case report. Journal of Neurosurgery, 29, 192-194.

Gautier-Smith, P. C. (1970). Parasagittal and Falx Meningiomas. Butterworths: London.

Haymaker, W., Rubinstein, L. J., and Miquel, J. (1972). Brain tumors in irradiated monkeys. Acta Neuropathologica (Berlin), 20, 267-277.
Jones, A. (1960). Supervoltage x-ray therapy of intracranial tumours. Annals of the Royal College of Surgeons of England, 27, 310-354.

Kent, S. P., and Pickering, J. E. (1958). Neoplasms in monkeys (Macacca mulatta): spontaneous and irradiation induced. Cancer, 11, 138-147.

Komaki, S., Komaki, R., Choi, H., and Correa-Paz, F. (1977). Radiation- and drug-induced intracranial neoplasms with angiographic demonstration. Neurologica Medico-Chirurgica, 17, 55-62.

Kurland, L. T. (1958). The frequency of intracranial and intraspinal neoplasms in the resident population of Rochester, Minnesota. Journal of Neurosurgery, 15, 627-641.

Kyle, R. H., Oler, A., Lasser, E. C., and Rosomoff, H. L. (1963). Meningioma induced by thorium dioxide. New England Journal of Medicine, 268, 80-82.

Li, F. P., Cassady, J. R., and Jaffe, N. (1975). Risk of second tumours in survivors of childhood cancer. Cancer, 35, 1230-1235.

Maurice-Williams, R. S., and Lucey, J. J. (1975). Raised intracranial pressure due to spinal tumours: three rare cases with a probable common mechanism. British Journal of Surgery, 62, 92-95.

Modan, B., Baidatz, D., Mart, H., Steinitz, R., and Levin, S. G. (1974). Radiation-induced head and neck tumours. Lancet, 1, 277-279.

Moertal, C. G. (1966). Multiple Primary Malignant Neoplasms. Their Incidence and Significance. Springer-Verlag: Berlin.

Mole, R. J. (1973). Late effects of radiation: carcinogenesis. British Medical Bulletin, 29, 78-83.

Mole, R. H. (1975). Ionizing radiation as a carcinogen: practical questions and academic pursuits. British Journal of Radiology, 48, 157-169.

Munk, J., Peyser, E., and Gruszkiewicz, J. (1969). Radiation induced intracranial meningiomas. Clinical Radiology, 20, 90-94.

Norwood, C. W., Kelly, D. L., Davis, C. H., and Alexander, E. (1974). Irradiation-induced mesodermal tumors of central nervous system: report of two meningiomas following $x$-ray treatment for gliomas. Surgical Neurology, 2, 161-164.

Russell, D. S., and Rubinstein, L. J. (1971). Pathology of Tumours of the Nervous System. Third Edition. Arnold: London.

Schoenberg, B. S., Greenberg, R. A., and Eisenberg, H. (1969). Occurrence of certain multiple primary cancers in females. Journal of the National Cancer Institute, 43, 15-32.

Schrantz, J. L., and Aroaz, C. A. (1972). Radiation induced meningeal fibrosarcoma. Archives of Pathology, 93, 26-31.

Smith, P. G., and Doll, R. (1976). Late effects of $\mathrm{x}$-irradiation in patients treated for metropathia haemorrhagica. British Journal of Radiology, 49, 224-232.

Tanaka, J., Garcia, J. H., Netsky, M. G., and Williams, J. P. (1975). Late appearance of meningioma at the site of partially removed 
oligodendroglioma. Case report. Journal of Neurosurgery, 43, 80-85.

Traynor, J. E., and Casey, H. W. (1971). Five-year follow-up of primate exposed to $55 \mathrm{MeV}$ protons. Radiation Research, 47, 143-148.

Waga, S., and Handa, H. (1976). Radiation-induced meningioma: with review of literature. Surgical Neurology, 5, 215-219.

Waltz, T. A., and Brownell, B. (1966). Sarcoma: a possible late result of effective radiation therapy for pituitary adenoma. Report of two cases. Journal of Neurosurgery, 24, 901-907.

World Health Organisation Report of Expert Committee (1977). Use of ionizing radiation and radionuclides on human beings for medical research, training, and nonmedical purposes. World Health Organisation Technical Reports Series 611. WHO: Geneva. 